\title{
Combined use of multi-seasonal high and medium resolution satellite imagery for parcel-related mapping of cropland and grassland
}

\author{
T. Esch ${ }^{a}, *, A$. Metz $^{b}$, M. Marconcini ${ }^{a}$, M. Keil $^{\text {a }}$ \\ a German Aerospace Center (DLR), German Remote Sensing Data Center (DFD), Oberpfaffenhofen, Germany \\ ${ }^{\mathrm{b}}$ University of Osnabrueck, Institute for Geoinformatics and Remote Sensing, Germany
}

\section{A R T I C L E I N F O}

\section{Article history:}

Received 2 May 2013

Accepted 6 December 2013

\section{Keywords:}

Multi-seasonal analysis

High and medium resolution data

Object-oriented classification

Grassland

Crop types

\begin{abstract}
A B S T R A C T
A key factor in the implementation of productive and sustainable cultivation procedures is the frequent and area-wide monitoring of cropland and grassland. In particular, attention is focused on assessing the actual status, identifying basic trends and mitigating major threats with respect to land-use intensity and its changes in agricultural and semi-natural areas. Here, multi-seasonal analyses based on satellite Earth Observation (EO) data can provide area-wide, spatially detailed and up-to-date geo-information on the distribution and intensity of land use in agricultural and grassland areas. This study introduces an operational, application-oriented approach towards the categorization of agricultural cropland and grassland based on a novel scheme combining multi-resolution EO data with ancillary geo-information available from currently existing databases. In this context, multi-seasonal high (HR) and medium resolution (MR) satellite imagery is used for both a land parcel-based determination of crop types as well as a cropland and grassland differentiation, respectively. In our experimental analysis, two HR IRS-P6 LISS3 images are first employed to delineate the field parcels in potential agricultural and grassland areas (determined according to the German Official Topographic Cartographic Information System - ATKIS). Next, a stack of seasonality indices is generated based on 5 image acquisitions (i.e., the two LISS scenes and three additional IRS-P6 AWiFS scenes). Finally, a C5.0 tree classifier is applied to identify main crop types and grassland based on the input imagery and the derived seasonality indices. The classifier is trained using sample points provided by the European Land Use/Cover Area Frame Survey (LUCAS). Experimental results for a test area in Germany assess the effectiveness of the proposed approach and demonstrate that a multi-scale and multi-temporal analysis of satellite data can provide spatially detailed and thematically accurate geo-information on crop types and the cropland-grassland distribution, respectively.
\end{abstract}

(C) 2013 Elsevier B.V. All rights reserved.

\section{Introduction}

A key aspect of the agricultural production in the European Union (EU) is the implementation of productive, sustainable and ecologically compatible cultivation forms. The cultivation forms as well as the related land-use intensity are mainly driven by environmental, economic and political factors that lead to constantly changing conditions and transformation processes in the cultivated landscape. Hence, a frequent and area-wide monitoring of the (agri-) cultural landscape is required in order to assess the current status, identify basic trends and mitigate major threats. This in turn is a prerequisite to warrant a sustainable development or implement effective adaptation and mitigation strategies. An established European-wide reporting system collecting key figures such as the acreage and type of crops is the statistical land-parcel identification

\footnotetext{
* Corresponding author. Tel.: +49 815328 3721; fax: +49 8153281445

E-mail address: Thomas.Esch@dlr.de (T. Esch).
}

system (LPIS) that is based on figures delivered by farmers (Devos and Milenov, 2010). The Land Use/Cover Area Frame Statistical Survey (LUCAS) aims at the frequent provision of land-use/land-cover (LULC) information for the EU member states (Martino and Fritz, 2008). However, the potential to characterise the spatial pattern of main crop types and grassland and their annual changes in a spatially detailed and comprehensive manner at local and regional scales is limited.

Satellite-based Earth Observation (EO) provides an ideal basis for the area-wide and spatially detailed provision of geo-data on the actual LULC and its changes in agricultural and grassland areas. In addition, the derived geo-information can be easily integrated into Geographical Information Systems (GIS) and/or combined with statistical or topographic data. The CORINE Land Cover (CLC) programme has been established as a pan-European EO-based LULC mapping initiative (EEA, 2007) delivering LULC data referring to 44 classes at a scale of $1: 100,000$. CLC data is available for 1990, 2000 and 2006, and an update for 2012 has been initiated. However, the actual updating interval of CLC is too static and the information on 
agricultural classes is too limited to assess key developments affecting the cultural landscape. These developments include changes in agricultural land use or land-use intensity, adaptations to changes in agricultural policy, increased use of biofuels or the loss of biodiversity in agricultural areas (Henle et al., 2008; Stoate et al., 2009).

The use of multi-seasonal EO data allows for the description of the type and intensity of agricultural land use, the quantitative and qualitative characterisation of changes in the cultural landscape or the updating and supplementation of geospatial or topographic databases (Hildebrandt, 1996; Bradley et al., 2007; Stoate et al., 2001, 2009). At the same time, cropland and grassland monitoring requires EO data covering large geographic areas at high temporal and spatial resolution with minimal costs (Wardlow and Egbert, 2008). However, currently available data covering large geographic areas have limited spatial resolution. Nevertheless, methods have been developed applying medium resolution (MR) data like NOAAAVHRR or MODIS and derived vegetation indices to describe the phenological behaviour of vegetation and different crops (Lunetta et al., 2010; Bradley et al., 2007; Wardlow and Egbert, 2008). Nevertheless, a limitation of these methods is their poor performance in areas characterised by small field parcels as it occurs in many regions within Europe. Accordingly, recent studies have started investigating the employment of high resolution (HR) data. Sai and Rao (2008) use IRS-P6 LISS-III and AWiFS data to discriminate rice, cotton, maize, sugarcane, mango, and forest within four study areas in India. Singh et al. (2011) describe the cropping pattern in the Indo-Gangetic plain of Uttar Pradesh, India, using seasonal IRS-P6 AWiFS data. Lobo et al. (1996) showed that the accuracy of cropland and grassland classification can be improved by focussing the analyses on objects (field parcels) instead of analysing the characteristics of single pixels. Bock et al. (2005) proved the effectiveness of object-oriented methods for habitat mapping at multiple scales for case studies in Germany and the United Kingdom. Conrad et al. (2010) classify irrigated crops based on field parcels in arid central Asia using SPOT and ASTER data. In another study, Conrad et al. (2011) investigated the potential of RapidEye time series data for the classification of crop rotations in the heterogeneous agricultural landscapes of irrigation systems in Central Asia. Turker and Ozdarici (2011) perform a comparative study of field-based crop classification using SPOT-4, SPOT-5, IKONOS and QuickBird data. Itzerott and Kaden (2006a,b) present an approach to approximate a universal class description for crops by means of multi-temporal satellite data, trying to reduce the influence of particular weather and soil conditions. Franke et al. (2012) discriminate between seminatural, extensively-used, intensively-used and tilled grasslands using multi-temporal RapidEye data for a study area in southern Germany.

It is worth noting that weather conditions (e.g., cloud cover) still hinder the employment of optical data for operational applications (Blaes et al., 2005). To overcome this drawback, some recent studies have been presented employing weather-independent synthetic aperture radar (SAR) data for cropland and grassland monitoring (Smith and Buckley, 2011; Lin et al., 2009; McNairn et al., 2009; Schuster et al., 2011; Metz et al., 2012).

The EC and European Environmental Agency (EEA) have initiated several programmes such as the FP7 Geoland2 project (Geoland, 2012) or the recently started GMES Initial Operations Land programme (GIO Land, 2012) which specifically address the development of EO-based service elements for the frequent provision of different agriculture and grassland layers at European level. In the framework of Geoland2-Euroland, Brodsky et al. (2011) use multi-seasonal IRS-P6 LISS-3 and/or AWiFS imagery to evaluate the influence of the temporal EO data coverage on the grassland/arableland classification. In particular, they obtain overall accuracies of $93 \%$ when considering five images and $85 \%$ when using three scenes acquired in April, July and October, respectively. A central element in this approach is the analysis of the seasonal behaviour of biophysical parameters such as the fraction of green vegetation cover (FCover) presented by Lacaze et al. (2011). In parallel to this, the research activities in the context of the Geoland2-Euroland project also included the application and assessment of the technique for cropland and grassland classification proposed by Metz (2009) demonstrated in a diploma study in the context of CORINE Land Cover 2006 in Germany.

However, the experience gained in the Geoland2-Euroland project with respect to large scale operational production of HR grassland products has shown that the tested methodologies still show certain potential for improvement. Here we identified three major directions of enhancement, (i) the capability to perform multi-sensor/multi-scale analyses in order to increase the temporal coverage with EO data takes (as a basis for an optimal description of seasonal characteristics), (ii) to classify grassland and crops at the level of field-parcels in order to provide more homogeneous and significant spectral and spatial properties (e.g., due to minimised spatial and temporal noise effects caused by outliers), and (iii) to allow for the integration of ancillary data available from currently existing geo-databases. Such geo-databases might be used to geometrically and thematically focus the analyses on specific areas or LULC categories of interest (e.g., using official topographic data or CORINE vector information), or to increase the degree of automation by minimising efforts to manually collect training data through the implementation of already available and frequently updated data sources at European-wide level (e.g., LUCAS point data). By integrating area-wide training data such as LUCAS point, the classification procedure can also be adapted more effectively to local geographical and landscape-specific conditions.

To realise these optimizations, this paper introduces an objectoriented approach for an effective multi-resolution analysis of seasonal EO data at field-parcel level. Thereby, the presented study aims at innovation in terms of effectively combining and enhancing existing base techniques in form of a specifically optimised and tailored workflow (and therewith increasing the applicability with respect to an operational production scenario) rather than introducing innovative algorithms or classification methods. To this aim, Section 2 introduces the methodological framework and workflow (with Section 2.1), the segmentation of the actual land parcels, and the identification of main crops and grassland. Section 3 presents the results of a quantitative accuracy assessment, whereas in Section 4 the conclusions are drawn and future perspectives are presented.

\section{Multi-scale analysis of seasonal time series data}

The differentiation of grassland and crop types can hardly be based on the mere interpretation of spectral properties alone, since the spectral characteristics of these LULC types significantly vary within the vegetation period. Moreover, spectral signatures of different crop types and grassland are quite similar to each other in some periods of the year, depending on their individual growth status, which in turn, are determined by phenology and cultivation. Crops show highly variable seasonal characteristics depending on the geographical region, local climate, sowing dates, weather conditions during the vegetation period, equipment and behaviour of the farmer, or cultivation cycle and harvesting times. In contrast, grassland features a more continuous seasonal development with some variation due to the management intensity (see Fig. 1). While the behaviour of natural grassland mostly follows the natural phenology as a function of the climatic conditions, semi-natural and managed grassland shows a more variable development subject to the influence of grazing cattle or mowing for fresh forage, silage or hay production. 


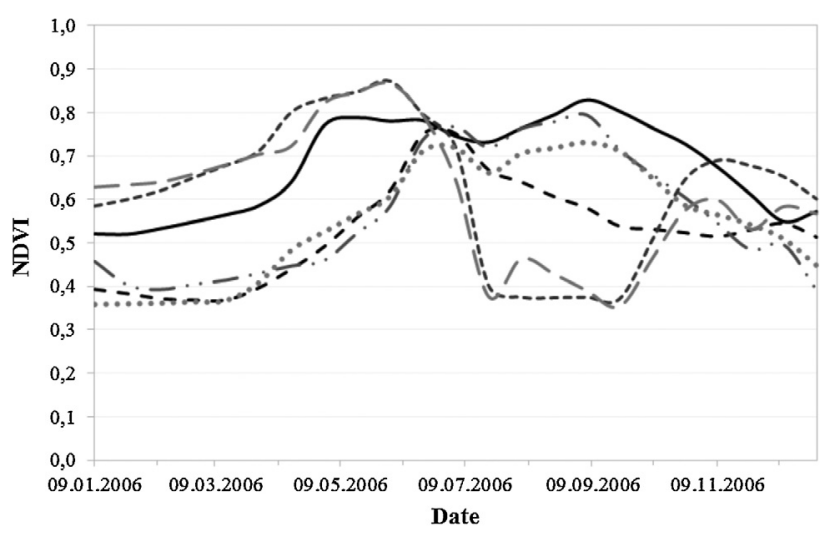

- Grassland - - - Potato - $\cdots$ Maize ----- Cereals - - Rape $\cdots \cdot . \cdot$ Sugar beet

Fig. 1. Variation of the Normalised Difference Vegetation Index (NDVI) throughout the vegetation period for semi-natural grassland and different crop types derived from MODIS data.

A robust classification procedure for effectively discriminating between grassland and main crops types therefore has to focus on the analysis of the seasonal development. The methods described in Section 1 demonstrate that multi-seasonal time series analyses of EO data represent an effective instrument to this purpose. However, the main challenge still lies in the collection of a cloud-free database covering key dates and seasons throughout the vegetation phase, while at the same time providing enough spatial detail to assure an accurate analysis at field-parcel level in regions with small patch sizes (as in many rural areas in Central Europe).

To effectively address this challenge, we propose a combined, object-oriented analysis of multi-seasonal HR and MR optical data. Thereby, one or two (e.g., spring and summer) HR satellite images (IRS-P6 LISS-3, $120 \mathrm{~km}$ swath width, $23.5 \mathrm{~m}$ spatial resolution) are used to properly delineate the different land parcels in the region of interest (by means of image segmentation techniques) and then employ additional MR satellite images (IRS-P6 AWiFS, $700 \mathrm{~km}$ swath width, $56 \mathrm{~m}$ spatial resolution) to optimally characterise the seasonal behaviour of the extracted segments. MR images are generally characterised by a large-swath width, a property that facilitates frequent coverages within comparably short periods of time and therewith increases the chances to collect a cloud-free seasonal dataset. After suitable pre-processing, meaningful land parcels are identified and extracted based on an image segmentation of the LISS-3 images. Next, all LISS-3 and AWiFS acquisitions are used to derive a defined set of seasonality indices for each segment. Then, thematic point data from the LUCAS database are used to train the C5.0 tree classifier that finally detects and categorises grassland and crop types. A schematic view of the entire methodological implementation is provided in Fig. 2 and described in detail in the following sub-sections.

\subsection{Study area, database and pre-processing}

The available EO database includes two LISS-3 scenes and three seasonal AWiFS images (ISRO, 2012) referring to an agricultural region in Mecklenburg Western Pomerania and Brandenburg, Germany. The area under investigation covers $23,012 \mathrm{~km}^{2}$ and is characterised by four main LULC categories, namely agriculture, woodland, settlement and water bodies (see Fig. 3).

The LISS-3 data were acquired on 5th May and 17th July, 2006, whereas the AWiFS images were acquired on 13th June, 17th July and 12th September, 2006. In addition, both for training the classifier and validating the results we used LUCAS geo-referenced points obtained from field surveys collected in 2006. For the investigated study area, 1796 points covering a total of 17 classes were selected from the LUCAS database. In this context, we excluded a priori sample points considered as unconfident by means of GIS-operations. However, since we are only interested in the LULC categories related to agriculture and grassland we exclusively considered the 1529 points referring to the 11 classes listed in Table 1 . Then, a further grouping into 5 more general agricultural categories including grassland and crop types exhibiting a comparable phenological behaviour was performed. Finally, vector data of the German Official Topographic Cartographic Information System (ATKIS) (AdV 2012) have been employed to create a mask of potential agricultural and grassland areas on which the EO-based analysis should be focused. To this aim, polygons related to grassland and agricultural classes have been dissolved and merged, and then exported as a single mask. The classification has been then carried out only over areas belonging to this mask.

The pre-processing procedure starts with an atmospheric correction of the LISS-3 and AWiFS images based on the ATCOR-2/3 software (Richter and Schläpfer, 2011) which allows minimising the effects of seasonal variations due to different atmospheric conditions. Next, the area covered by the full dataset (composed of the two LISS and three AWiFS scenes) is outlined and clipped into each of the single images. This set of radiometrically optimised and clipped data serves as a basis for the following steps. In particular, first the NDVI is computed for the 5 scenes in order to describe the status of the vegetation at the different dates. Then, the seasonal development is quantitatively described by calculating a set of four statistical seasonality parameters for each pixel from the 5 NDVI images, namely the seasonal minimum, the seasonal maximum, the seasonal mean and the range between minimum and maximum. The 5 images and their corresponding NDVI as well as the four seasonality features extracted are then combined into a single data stack.

\subsection{Land-parcel extraction}

The optimal spatial unit for our classification task are the land parcels on which grassland and different crop types are cultivated. These can be optimally retrieved by employing advanced segmentation approaches that group pixels of the original EO images into meaningful segments with homogeneous characteristics. Furthermore, this also allows performing an object-oriented classification which prevents salt-and-pepper effects typical for pixel-based approaches in agricultural areas.

In this study, the image segmentation has been carried out using the Definiens Developer software (version 8.7), whereas a special optimisation procedure has been applied to achieve an accurate representation of the spatially heterogeneous landscape structures. This approach has been first introduced by Esch et al. (2008) and aims at the minimisation of both over- and under-segmentation in order to attain more accurate results. To this aim, the optimisation procedure iteratively combines a sequence of multi-scale segmentation, feature-based classification, and classification-based object refinement. In a first step, a segment level is created that exactly reflects the vector geometry of the agriculture mask extracted from the ATKIS vector information. Then, the polygons of the mask are subdivided by means of the segmentation optimisation process that is conducted solely using the two HR LISS-3 scenes with 5 iterations and a scale parameter increasing from 20 for the first iteration to 100 for the last iteration (meaning a step of 20 from iteration to iteration). The result of the image segmentation (performed by means of the Multi-resolution Segmentation algorithm; Benz et al., 2004) is shown in Fig. 4. As a last step, the mean values of all the features (i.e., the spectral bands and NDVI of the 5 input scenes and the seasonality parameters) are calculated for and assigned to each parcel of the final image segmentation. 


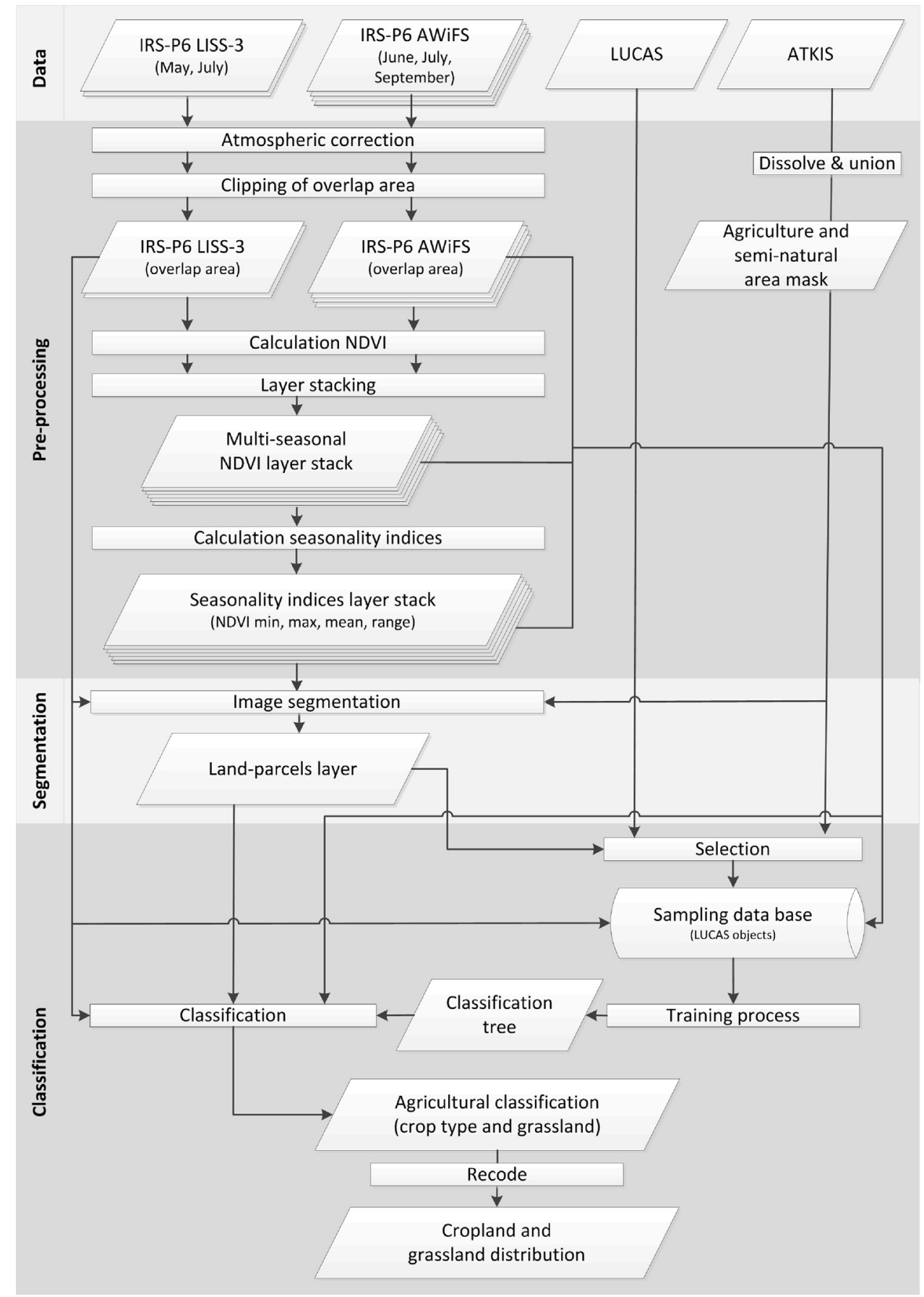

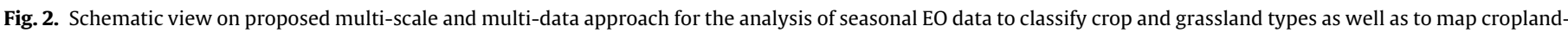
grassland distribution.

Table 1

LUCAS categories considered in our analysis and corresponding available labelled samples.

\begin{tabular}{|c|c|c|c|}
\hline LUCAS code & LUCAS class name & No. of sample points & Main category \\
\hline B11 & Common wheat & 296 & \\
\hline B13 & Barley & 173 & \\
\hline B14 & Rye & 98 & 211 (Cereals) \\
\hline B15 & Oats & 14 & \\
\hline B18 & Triticale & 50 & \\
\hline B16 & Maize & 84 & 216 (Maize) \\
\hline B21 & Potatoes & 14 & 270 (Roterons) \\
\hline B22 & Sugar Beat & 17 & 220 (Root crops) \\
\hline B32 & Rape & 246 & 232 (Rape) \\
\hline E01/02 & Grassland & 537 & 400 (Grassland) \\
\hline
\end{tabular}



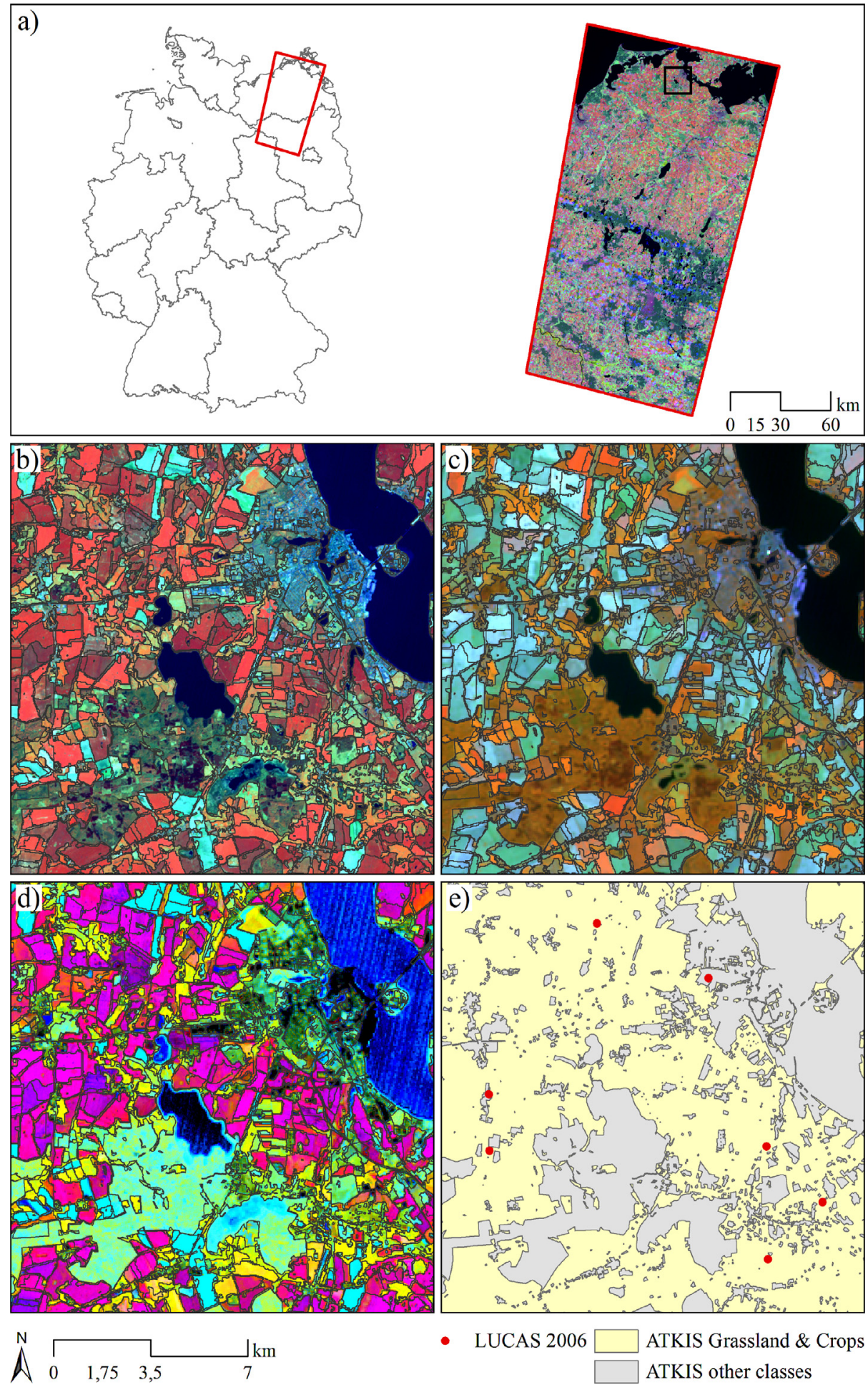

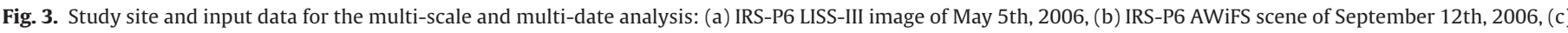

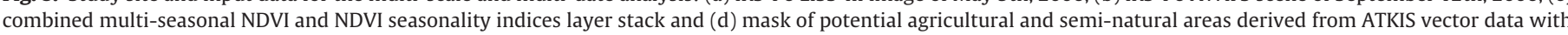
LUCAS sample points overlaid.

\subsection{Identification of main crops and grassland}

The classification of grassland and crop types starts with the semi-automated generation of a sampling database for training the C5.0 decision tree classifier (Quinlan, 1992). Different studies (i.e., Bailey and Boryan, 2010; Fisette et al., 2006; DeFries and Chan, 2000; Friedl and Brodley, 1997) have proven the effectiveness of $\mathrm{C} 5.0$ in addressing classical challenges arising when dealing with time series and LULC analyses (e.g., non-Gaussian statistical distribution of the classes in the feature space, missing values due to cloud cover, etc.). Since the algorithm automatically selects the attributes relevant for the class assignment along with the suitable thresholds, no manual adjustment of the classification parameterisation is required as long as the designated classes are adequately represented by the training dataset. 

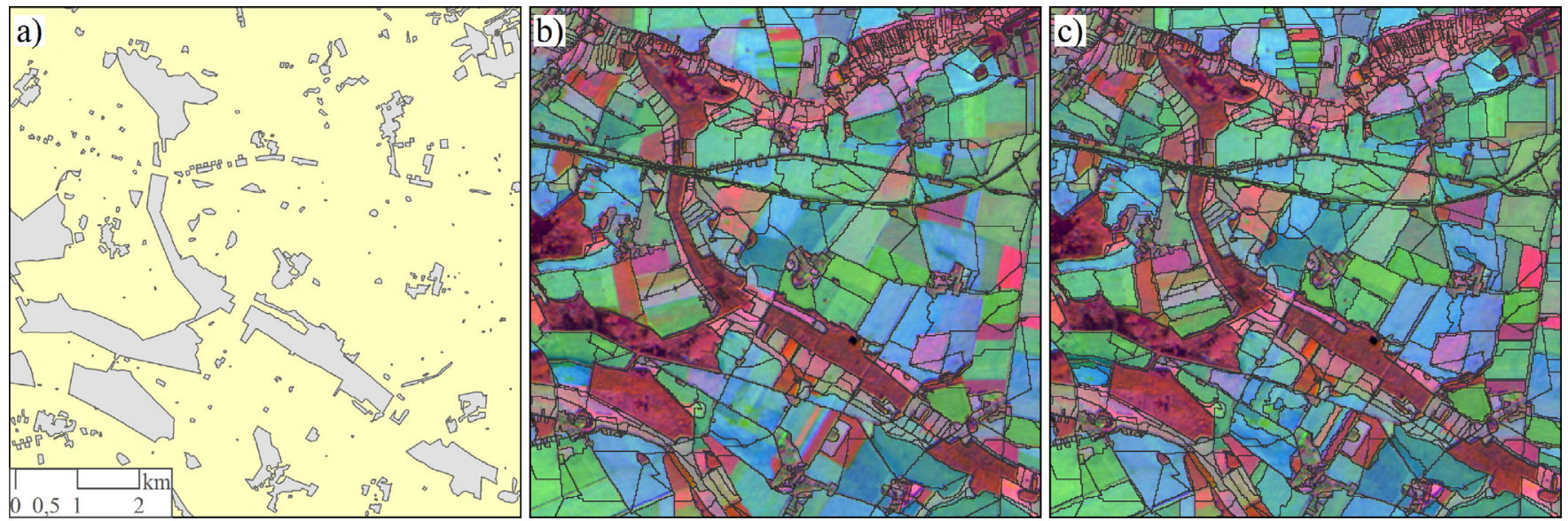

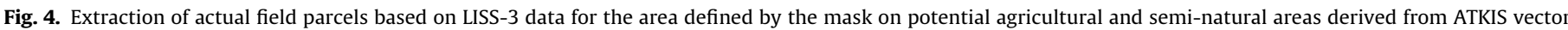
data (Geobasis data $^{\odot}$ German Federal Agency for Cartography and Geodesy - www.bkg.bund.de).

In preparation of the training and classification procedure, the LUCAS point data is pre-selected using GIS-operations in order to exclude sample points that are considered as unconfident, e.g., because they are positioned at the border between two land-parcel segments. From the available 1529 labelled samples, 50\% have been used for training the classifier, whereas the other $50 \%$ have been used for validating the results. For the training process itself only image objects of the final segmentation intersecting with a LUCAS point are used. Thereby, the C5.0 algorithm automatically creates a classification decision tree that relates properties of each training object to its assigned LUCAS LULC class with no need for any further user-defined parameters. The set of input features provided for each object includes the spectral bands of the 5 input scenes as well as the NDVI and seasonality layers. The created classification tree is then applied to all image objects for discriminating between grassland and the four considered main crop types (see Fig. 2). The final step includes the generalisation of these four crop types to one "agriculture" class in order to obtain a final cropland-grassland classification.

\section{Results}

The final results of the classification procedure described in Section 2.3 as well as the generalised cropland-grassland classification are illustrated in Fig. 5. The quantitative assessment shows an overall accuracy (OA) of $86 \%$ and a Kappa coefficient of 0.79 when considering 5 classes. Table 2 gives a detailed overview of the error statistic for the classification - including producer's (PA) and user's accuracies (UA). Cereals (class 211), rape (class 232), and grassland (class 400 ) have been classified with PA and UA higher than $85 \%$. The small confusion between grassland and cereals as well as cereals and rape can be disregarded. In contrast, maize (class 216) and root crops (class 220) show slightly lower accuracies (PA and UA) between $63 \%$ and $78 \%$. One can notice that root crops have partly been classified as maize and maize has been partly classified as grassland. This is due to the fact that root crops and maize as well as maize and grassland have a similar seasonal and spectral behaviour (see Fig. 1) resulting in corresponding misclassifications. Furthermore, the number of training and validation points for maize and

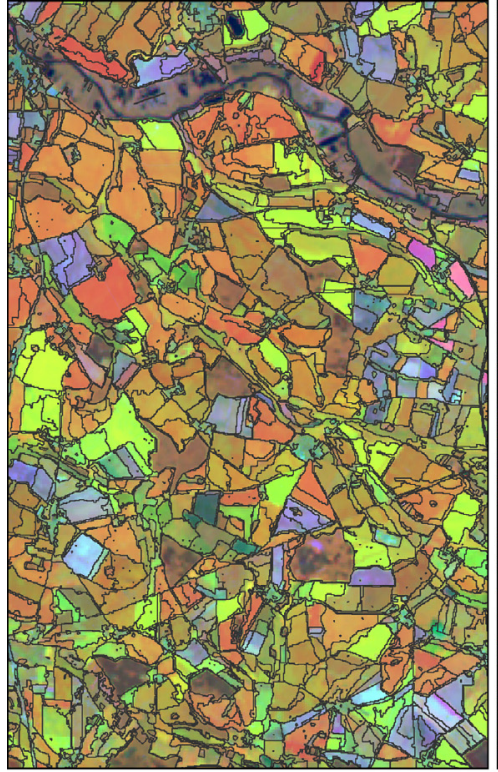

$\square$ Cereal $\square$ Maize

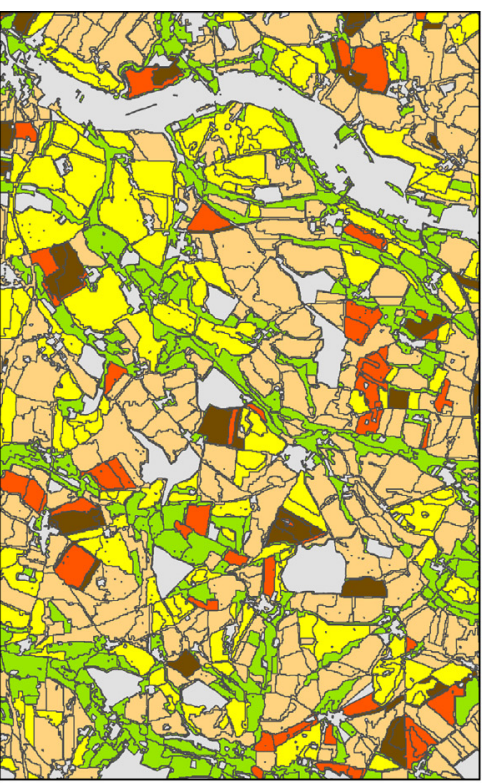

Root crops $\square$ Rape $\square$ Grassland

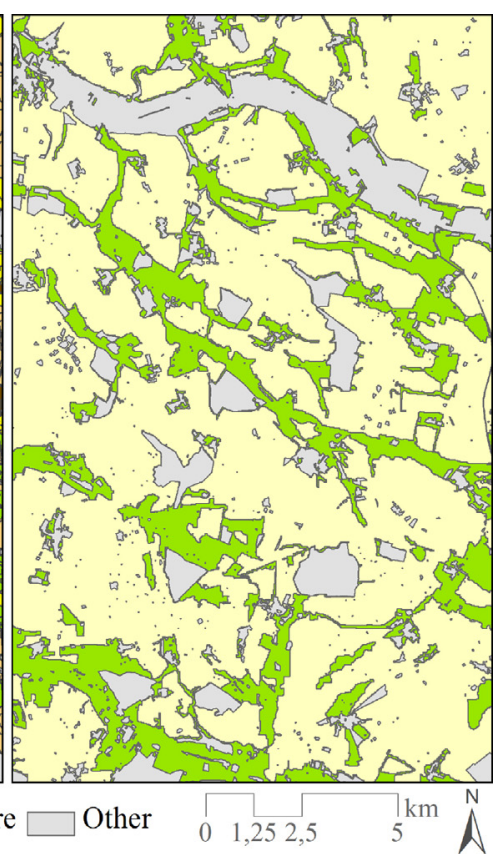

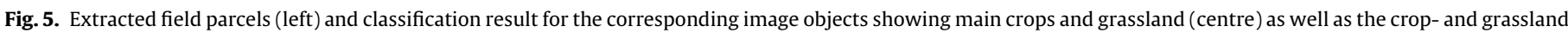
distribution (right) for a subset of the test region. 
Table 2

Confusion matrix and corresponding percentage overall accuracy referring to the classification of main crop types and grassland.

\begin{tabular}{|c|c|c|c|c|c|c|c|}
\hline Class & 211 & 216 & 220 & 232 & 400 & Samples & UA \\
\hline 211 (Cereals) & 269 & 7 & 2 & 10 & 27 & 315 & 85.4 \\
\hline 216 (Maize) & 1 & 33 & 1 & 0 & 7 & 42 & 78.6 \\
\hline 220 (Root crops) & 0 & 4 & 10 & 0 & 1 & 15 & 66.7 \\
\hline 232 (Rape) & 8 & 0 & 1 & 110 & 4 & 123 & 89.4 \\
\hline 400 (Grassland) & 20 & 8 & 1 & 5 & 243 & 268 & 87.3 \\
\hline Samples & 298 & 52 & 15 & 125 & 273 & 763 & \\
\hline PA & 90.3 & 63.5 & 66.7 & 88.0 & 85.7 & & OA: 86.0 \\
\hline
\end{tabular}

root crops is quite small so that the error statistics react more sensitive towards slight variations in the number of classification errors. Nevertheless, when addressing the cropland-grassland discrimination (as reported in the right image of Fig. 5) the OA is $90 \%$ and Kappa is 0.79, with PA and UA always higher than $92 \%$ for cropland and PA and UA always higher than $85 \%$ for grassland.

In addition to the described analysis, we classified the images using all 11 original agricultural LUCAS classes characterising the study region and obtained a final OA of $70 \%$. We also compared the results with the outcome of classifications based on one (05th May, 2006) and two (05th May, 2006, 12th September, 2006) scenes. Here, OA's of $69 \%$ (single-date) and 76\% (dual-date) are achieved when investigating the 5-class case.

\section{Conclusions and future perspectives}

The results of our study indicate that seasonal time series analyses afford the accurate identification and characterisation of main crop types and grassland. Key issues in this context are the existence of adequate reference information (in terms of number of samples and thematic reliability) and the availability of a constant seasonal and spatial coverage with multi-seasonal satellite data. A limiting factor for the required multi-seasonal EO data analysis is the frequently occurring cloud coverage in time series of optical sensors that clearly constraints the data availability - especially regarding HR imagery and data requirements for specific dates of the year. This factor becomes particularly critical with respect to large-area assessments. The study demonstrated that the combination of HR and MR imagery represents a promising approach to increase the chances to achieve a significant coverage with seasonal data while at the same time assuring a high spatial detail of the analysis (e.g., addressing the field parcel level). An alternative approach to warrant optimal data availability is the use of radar data (e.g., TerraSAR-X, TanDEM-X or Radarsat-2) which can be collected independently from weather and environmental conditions.

Considering the seasonal development of major crops and grassland (see Fig. 1), it appears that the harvesting period is best fitted to differentiate between cereals and grassland. However, in this time interval the NDVI still shows similarities between grassland and maize as well as grassland and root crops. Therefore, the separation of arable crops and grassland requires additional data acquisitions during the spring season. In comparison to arable land, pasture land shows a more constant and homogenous behaviour with respect to the development of green vegetation over the entire vegetation period. Analysing its seasonal behaviour, the NDVI of grassland shows a distinct increase in spring (March, April) before it levels in early summer, followed by a slight drop during the dry season and a constant decrease from late summer to winter. Meadows affected by hay mowing feature a higher dynamic during the summer period. For arable crops, the vegetation development starts at different time slots. After a significant increase during the growing phase the NDVI levels or slightly decreases in the maturation before it finally drops significantly during the harvesting period.

The presented object-based concept provides effective options for the realisation of a multi-sensor/data, multi-scale and multi-seasonal approach that in turn provides the flexibility which is required for the realisation of multi-seasonal analyses at regional or national scale. At the same time this approach represents a promising methodology for the frequent monitoring of trends and transformations of LULC, e.g. extensification or intensification in terms of a conversion from cropland to pastures or vice versa. It also facilitates the (semi-)automated update or thematic extension of existing geo-data layers with respect to general changes in LULC or relative changes in the intensity of use or productivity. In order to further improve the workflow and optimise the operability of the proposed approach, in the near future we plan more extensive, area-wide tests over different regions within Europe.

\section{Acknowledgements}

The authors thank the European Commission for the funding of the FP7 GMES project of Geoland2-Euroland in which context the basic techniques presented in this publication were further stimulated and developed. The authors would also like to thank the German Federal Environment Agency for funding the initial technical developments, the German Federal Agency for Cartography and Geodesy (BKG) for providing GeoBasis-DE data (ATKIS) for this study and the GAF AG and EUROMAP GmbH for the provision of IRS-P6 AWiFS data in the context of the IRS-P6 Scientific Data Pool.

\section{References}

AdV, 2012. Arbeitsgemeinschaft der Vermessungs-verwaltungen der Länder der Bundesrepublik Deutschland: Erläuterungen zum ATKIS-Objektartenkatalog der Arbeitsgemeinschaft der Vermessungsverwaltungen der Länder der Bundesrepublik Deutschland, Available URL: http://www.atkis.de (accessed 28.04.12).

Bailey, J.T., Boryan, C., 2010. Remote sensing uses in agriculture at the nationa agricultural statistics service. In: Proceedings of 5th Conference on Agricultural Statistics, Integrating Agriculture into the National Statistical System (ICAS-V), 12-15 October 2010, Kampala, Uganda.

Benz, U.C., Hofmann, P., Willhauck, G., Lingenfelder, M., 2004. Multi-resolution, object-oriented fuzzy analysis of remote sensing data for GIS-ready information. ISPRS Journal of Photogrammetry and Remote Sensing 58, 239-258.

Blaes, X., Vanhalle, L., Defourny, P., 2005. Efficiency of crop identification based on optical and SAR image time series. Remote Sensing of Environment 96, 352-365.

Bock, M., Xofis, P., Mitchley, J., Rossner, G., Wissen, M., 2005. Object-oriented methods for habitat mapping at multiple scales - case studies from Northern Germany and Wye Downs, UK. Journal for Nature Conservation 13, 75-89.

Bradley, B., Jacob, R., Hermance, J., Mustard, J., 2007. A curve fitting procedure to derive inter-annual phenologies from time series of noisy satellite NDVI data. Remote Sensing of Environment 106 (2), 137-145.

Brodsky, L., Gangkofner, U., Jacob, P., Keil, M., Soukup, T., 2011. Geoland2 Technical Note on HR Grassland Layer Product Specification, Available URL: http://www.gmes-geoland.info/fileadmin/geoland2/redakteur/pdf/Project. Documentation/Service_Specification/TechnicalProductSpecification_HR Grassland Layer I2.pdf

Conrad, C., Fritsch, S., Zeidler, J., Rücker, G., Dech, S., 2010. Per-field irrigated crop classification in arid Central Asia using SPOT and ASTER data. Remote Sensing 2 (4), 1035-1056

Conrad, C., Machwitz, M., Schorcht, G., Löw, F., Fritsch, S., Dech, S., 2011. Potentials of RapidEye time series for improved classification of crop rotations in heterogeneous agricultural landscapes: experiences from irrigation systems in Centra Asia. In: Proceedings of SPIE, 8174, SPIE Remote Sensing 2011, 19-22 September 2011, Prague, Czech Republic, ISBN 9780819488015.

DeFries, R.S., Chan, J.C-W., 2000. Multiple criteria for evaluating machine learning algorithms for land cover classification from satellite data. Remote Sensing of Environment 74, 503-515.

Devos, W., Milenov, P., 2010. LPIS Applications and Quality - Report of the Land Parcel Identification System (LPIS) Annual Workshop Copenhagen (Denmark), 
20-22 September 2010. Joint Research Centre of the European Commission, Ispra, Italy, JRC62599.

EEA (Ed.), 2007. CLC 2006 Technical Guidelines. EEA Technical Report, No 17/2007, Copenhagen., Available URL: http://www.eea.europa.eu/publications/ technical_report_2007_17 (accessed 19.12.12).

Esch, T., Thiel, M., Bock, M., Roth, A., Dech, S., 2008. Improvement of image segmentation accuracy based on multi-scale optimization procedure. IEEE Geoscience and Remote Sensing Letters 5 (3), 463-467.

Fisette, T., Chenier, R., Maloley, M., Gasser, P.Y., Huffman, T., White, L., Ogston, R., Elgarawany, A., 2006. Methodology for a Canadian agricultural land cover classification. In: Proceedings of 1st Int. Conference on Object-based Image Analysis, 04-05 July 2006, Salzburg, Austria.

Franke, J., Keuck, V., Siegert, F., 2012. Assessment of grassland use intensity by remote sensing to support conservation schemes. Journal for Nature Conservation 20 (3), 125-134.

Friedl, M.A., Brodley, C.E., 1997. Decision tree classification of land cover from remotely sensed data. Remote Sensing of Environment 61, 399-409.

Geoland (2012). Available URL: www.gmes-geoland.info (accessed 19.12.12).

Hildebrandt, G., 1996. Fernerkundung und Luftbildmessung für Forstwirtschaft Vegetationskartierung und Landschaftsökologie, first ed. Wichmann, Heidelberg.

GIO Land (2012). Available URL: http://www.eea.europa.eu/themes/landuse/gioland/gio-land (accessed 19.12.12).

Henle, K., Alard, D., Clitherow, J., Cobb, P., Firbank, L., Kull, T., et al., 2008. Identifying and managing the conflicts between agriculture and biodiversity conservation in Europe - a review. Agriculture, Ecosystems and Environment 124, 60-71.

ISRO (2012). Available URL: http://www.isro.org/satellites/irs-p6resourcesat-1.aspx

Itzerott, S., Kaden, K., 2006a. Spektrale Normkurven - eine notwendige Voraussetzung für die Klassifizierung der Fruchtartenverteilung aus Fernerkundungsdaten (Spectral standard curves - a precondition of crop distribution classification in agriculture from satellite data). Photogrammetrie, Fernerkundung, Geoinformation 3, 509-518.

Itzerott, S., Kaden, K., 2006b. Ein neuer Algorithmus zur Klassifizierung landwirtschaftlicher Fruchtarten auf Basis spektraler Normkurven (An algorithm to classify agricultural crops on the basis of spectral standard curves). Photogrammetrie, Fernerkundung, Geoinformation 6, 509-518.

Lacaze, R., Baret, F., Camacho, F., d’Andrimont, R., Freitas, S.C., Pacholczyk, P., Poilve, H., Smets, B., Tansey, K.W., Wagner, W., Calvet, J.-C., Balsamo, G., Kidd, R., Makhmara, H., Weiss, M., Bradley, A., 2011. geoland2 - towards an operational GMES land monitoring core service: the biogeophysical parameter core mapping service. In: Proceedings of the 34th International Symposium on Remote Sensing of Environment, April 2011, Sydney, Australia.

Lin, H., Chen, J., Pei, Z., Zhang, S., Hu, X., 2009. Monitoring sugarcane growth using ENVISAT ASAR data. IEEE Transactions on Geoscience and Remote Sensing 47 (8), 2572-2580.

Lobo, A., Chic, O., Casterad, A., 1996. Classification of Mediterranean crops with multisensor data: Per-pixel versus per-object statistics and image segmentation. International Journal of Remote Sensing 17, 2385-2400.
Lunetta, R.S., Shao, Y., Ediriwickrema, J., Lyon, J.G., 2010. Monitoring agricultura cropping patterns across the Laurentian Great Lakes Basin using MODIS-NDVI data. International Journal of Applied Earth Observation and Geoinformation 12 (2), 81-88.

Martino, L., Fritz, M., 2008. New Inside into Land Cover and Land Use in Europe Land Use/Cover Area Frame Statistical Survey: Methodology and Tools. Eurostat - Statistics in Focus 33, European Communities, Luxembourg.

McNairn, H., Shang, J., Champagne, C., Jiao, X., 2009. TerraSAR-X and RADARSAT-2 for crop classification and acreage estimation. In: Proceedings of IEEE International Geoscience and Remote Sensing Symposium (IGARSS) 2009, Cape Town, II-898II-901.

Metz, A., Schmitt, A., Esch, T., Reinartz, P., Klonus, S., Ehlers, M., 2012. Synergetic use of TerraSAR-X and Radarsat-2 time series data for identification and characterization of grassland types - a case study in Southern Bavaria. In: Proceedings IGARSS 2012, 22-27 July, Munich, Germany.

Metz, A., (Diploma thesis) 2009. Knowledge Based Update of DLM-DE with Remote Sensing and Geodata for Deduction of a High Resolution Land Use/Land Cover Mapping using CORINE Land Cover. Dresden University of Technology.

Quinlan, J.R., 1992. C4. 5 Programs for Machine Learning. Morgan Kaufmann, San Mateo, CA.

Richter, R., Schläpfer, D., 2011. Atmospheric/Topographic Correction for Satellite Imagery. Wessling, Germany.

Schuster, C., Ali, I., Lohmann, P., Frick, A., Förster, M., Kleinschmidt, B., 2011. Towards detecting swath events in TerraSAR-X time series to establish NATURA 2000 grassland habitat swath management as monitoring parameter. Remote Sensing 3 (7), 1308-1322.

Sai, M.S., Rao, P.N., 2008. Utilization of Resourcesat-1 data for improved crop discrimination. International Journal of Applied Earth Observation and Geoinformation 10, 206-210.

Singh, N.J., Kudrat, M., Jain, K., Pandeya, K., 2011. Cropping pattern of Uttar Pradesh using IRS-P6 (AWiFS) data. International Journal of Remote Sensing 32 (16), 4511-4526.

Smith, A.M., Buckley, J.R., 2011. Investigating RADARSAT-2 as a tool for monitoring grassland in western Canada. Canadian Journal of Remote Sensing 37 (1) 93-102.

Stoate, C., Boatman, N.D., Borralho, R.J., Carvalho, C.R., de Snoo, G.R., Eden, E., 2001. Ecological impacts of arable intensification in Europe. Journal of Environmental Management 63 (4), 337-365.

Stoate, C., Báldi, A., Beja, P., Boatman, N.D., Herzon, I., van Doorn, A., et al., 2009. Ecological impacts of early 21st century agricultural change in Europe - a review. Journal of Environmental Management 91 (1), 22-46.

Turker, M., Ozdarici, A., 2011. Field-based crop classification using SPOT4, SPOT5 IKONOS and QuickBird imagery for agricultural areas: a comparison study. International Journal of Remote Sensing 32 (24), 9735-9768.

Wardlow, B.D., Egbert, S.L., 2008. Large-area crop mapping using time-series MODIS 250 m NDVI data: an assessment for the U.S. Central Great Plains. Remote Sensing of Environment 112 (3), 1096-1116. 